\title{
Long-term clinical and echocardiographic outcomes of extensive septal myectomy for hypertrophic obstructive cardiomyopathy in Chinese patients
}

Lei Yao ${ }^{1 *}$, Li Li ${ }^{1}$, Xiong-Jun Lu², Yan-Ling Miao ${ }^{1}$, Xiao-Ning Kang ${ }^{1}$ and Fu-Jian Duan ${ }^{3}$

\begin{abstract}
Background: There has been limited data addressing outcomes of extensive septal myectomy in Chinese patients with hypertrophic obstructive cardiomyopathy (HOCM). In this study, the objective was to evaluate the clinical and echocardiographic outcomes of extensive septal myectomy in a relative large number of Chinese HOCM patients over long-term follow-up.

Methods: We retrospectively studied 139 consecutive HOCM patients (age $43 \pm 15$ years, $37 \%$ male) who underwent extensive left ventricular septal myectomy. During the perioperative period, all patients were examined by echocardiography. All-cause death and cardiac death were considered as primary endpoints during follow-up. Perioperative data was obtained by retrospective review of institutional surgical databases. Follow-up data of echocardiography and clinical status was recorded through outpatient interview.

Results: Perioperative events consisted of arrhythmia, retraction injury to aortic valve leaflets, pleural effusion, and hemodialysis and the use of intra-aortic balloon pump. There was no in-hospital mortality. The follow-up period averaged $5.6 \pm 0.9$ years and overall survivals were 100.0, 99.3, 99.3, 98.5 and $97.8 \%$ at 1, 2, 3, 4 and 5 years, respectively. Left ventricular outflow tract (LVOT) gradient decreased form preoperative $84 \pm 17 \mathrm{mmHg}$ to $12 \pm 3 \mathrm{mmHg}$ at 2.5 years after surgery and it further reduced to $6 \pm 3 \mathrm{mmHg}$ at 5 years after surgery $(P<0.05)$. Compared with the preoperative levels, interventricualr septal thickness decreased by $32 \%$ while diastole left ventricular inner diameter approximately increased by $10 \%$ and ejection fraction (EF) was significantly elevated during follow-up $(P<0.05)$. By echocardiography detection, mitral regurgitation was ameliorated for HOCM patients after surgery. There was significant improvement in New York Heart Association (NYHA) class. The proportion of NYHA III and IV decreased from preoperative 58 to $19 \%$ at 2.5 years after surgery and it reduced to $11 \%$ at 5 years after operation.
\end{abstract}

Conclusion: Extensive septal myectomy offers minimal operative risk and provides long-term relief for LVOT obstruction in Chinese HOCM patients.

Keywords: Hypertrophic cardiomyopathy, Hypertrophic obstructive cardiomyopathy, Extensive septal myectomy

\footnotetext{
* Correspondence: yaolei_pubmed@sina.com

'Second Division of Ultrasound Diagnosis, Cangzhou Central Hospital, 16

Xin-Hua-West Street, Cangzhou, Hebei 061001, People's Republic of China

Full list of author information is available at the end of the article
} 


\section{Background}

Hypertrophic cardiomyopathy (HCM) is estimated to affect $0.2 \%$ of the population $[1,2]$. As the most common inherited cardiac disease, HCM is characterized by asymmetrical septal hypertrophy [3, 4]. The phenotypes are ranging from minor to severe life-threatening status [5]. Left ventricular outflow tract (LVOT) obstruction is responsible for disabling symptoms in a large proportion of patients and confers a worse prognosis. HCM is the most common cause of sudden cardiac death (SCD) in people aged less than 35 years. In fact, it is more common for HCM patients to develop to severe progressive heart failure than SCD.

Septal myectomy is considered as the gold standard for septal reduction therapy in patients with dynamic LVOT obstruction [6]. The long-term mortality for hypertrophic obstructive cardiomyopathy (HOCM) patients with septal myectomy reduction therapy decreases to $1.4-1.8 \%[7,8]$. Septal myectomy has contributed to the overall reduction in mortality and provided survival equivalent to that of the general population [9]. The operative technique of HOCM has undergone evolution from classic Morrow surgery to extensive resection. Extensive septal myectomy surgery has evolved into a comprehensive repair technique for LVOT obstruction and abnormality of the mitral apparatus [10]. Extension of the myectomy area leads to improved surgical effect. Currently, there are limited data addressing long-term outcome of extensive septal myectomy in Chinese patients with HOCM. In the present study, we sought to report the early and late clinical and echocardiographic outcomes of Chinese HOCM patients who underwent extensive septal myectomy surgery.

\section{Methods}

\section{HOCM patients}

This study was carried out in 139 consecutive HOCM patients treated with extensive surgical myectomy in Cangzhou Central hospital and Shandong Chinese Medical Hospital from Jan 1, 2008 to May 31, 2011. Patients were eligible for inclusion in surgical intervention if they met the following two criteria [11]: 1) LVOT pressure gradient $\geq 50 \mathrm{mmHg}$ at rest or with physiological provocation by transthoracic echocardiography; 2) presence of severe symptoms despite prior appropriate medical therapy with beta-receptor blocker and calcium channel blocker. All patients were evaluated by consultant cardiologists. Although they were given medical therapy, they still had severe symptoms attributable to LVOT obstruction. The review of hospital records and analyses of preoperative data, operative reports, postoperative and follow-up echocardiography were carried out. In this study, perioperative period was defined as time period from surgical preparation to 30 days after extensive septal myectomy. The study had full approval from the Ethics Boards of Cangzhou Central hospital and Shandong Chinese Medical Hospital.

\section{Surgical procedure}

Operations were carried out under mild hypothermic cardiopulmonary bypass with total anesthesia as previously described $[12,13]$. The heart and ascending aorta were exposed by a longitudinal median incision in sternum. Cannulas were inserted into superior vena cava, inferior vena cava and ascending aorta to establish cardiopulmonary bypass. Through a transverse aortotomy, the aortic valve was exposed and cardiac asystole was induced by cold blood antegrade cardioplegia. Hypertrophic septum and mitral valve were exposed sufficiently by pulling right coronary aortic valve. A Ross retractor was used to display the muscular septum. The superior borderline of septal resection located at $3 \mathrm{~mm}$ below right coronary sinus valve. Resection started from middle of right aortic sinus and moved 10-12 mm horizontally toward commissure of left sinus valve and right sinus valve. Longitudinal resection usually reached the root of mitral papillary muscle, length of which ranged from 45 to $50 \mathrm{~mm}$. In order to reduce LVOT gradient, the thicknesses of the left ventricular wall and interventricular septum need to be nearly normal by visual inspection.

The following extended procedures were performed as previously described $[14,15]: 1)$ The resection was continued toward the mitral valve annulus and apically to the bases of the papillary muscles. 2) All areas of papillary muscle fusion to the septum or ventricular free wall are divided, and anomalous chordal structures and fibrous attachments of the mitral leaflets to the ventricular septum are excised. 3) Plication of the anterior mitral leaflet (AML) was performed if there were indications by selection criteria including floppy and lax anterior leaflet, $\mathrm{AML} \geq 3.0 \mathrm{~cm}$, mitral regurgitation $\geq 2+$, systolic anterior motion (SAM), and/or absence of rheumatic or other intrinsic mitral valve disease. Intraoperative transesophageal echocardiography (TEE) was used routinely. TEE assessment was performed after weaning from cardiopulmonary bypass to evaluate adequacy of LVOT and mitral valve function.

Postoperative monitor was carried out to maintain proper cardiac preload and appropriate colloid infusion. Beta-receptor blocker or calcium-channel blocker was applied routinely. Low-dose vasoactive drugs were used when hemodynamic circulation fluctuated.

\section{Echocardiography}

During hospital stay, preoperative transthoracic echocardiography was performed for HOCM patients and intraoperative TEE was applied routinely. The adequacy of the resection and the LVOT gradient were assessed immediately 
by transthoracic echocardiography after surgery and transthoracic echocardiography was repeated before or on the day of hospital discharge. During outpatient follow-up period, patients had transthoracic echocardiography detection at every visit. A careful analysis of septal hypertrophy, abnormalities of the mitral valve, and subvalvular apparatus was performed. LVOT gradient was detected at rest and with provocation by transthoracic echocardiography. Specific details of mitral valve length, SAM, and mitral regurgitation were evaluated. Images were captured on cine loops at the time of the detection. M-mode from long axis view was used to measure interventricualr septal (IVS) thickness and diastole left ventricular inner diameter $\left(\mathrm{LVID}_{\mathrm{d}}\right)$. Mmode from short axis view was used to measure thickness of left ventricular wall. Ejection fraction (EF) was automatically calculated by the measurement package.

\section{Follow-up}

The follow-up period averaged $5.6 \pm 0.9$ years for HOCM patients. Follow-up data were derived from medical charts and LVOT gradient information was obtained from the record of transthoracic echocardiography detection at every outpatient visit. Our primary endpoints included allcause death and cardiac death during follow-up. Cardiac death was defined as a death resulting from heart failure or SCD. SCD was defined as an abrupt loss of consciousness within $1 \mathrm{~h}$ after the onset of acute symptoms, and the cause of death could not be attributed in the postmortem examination. All patients were assigned New York Heart Association (NYHA) classification based on symptoms.

\section{Statistical analysis}

Continuous variables were expressed as mean \pm SD otherwise described as proportion. $\chi^{2}$ test was used to compare categorical variables. For continuous variables, one-way ANOVA was used to analyze the data among three groups and then paired $t$ test was performed for the comparison between two groups. The Kaplan-Meier method was used to draw survival curve and calculate survival rate and cumulate hazard. Difference was considered statistically significant when $P<0.05$. All statistical tests were performed using SPSS software package 19.0 for Windows.

\section{Results}

\section{Clinical characteristics}

Clinical characteristics of 139 HOCM patients with mean age $43 \pm 15$ years were shown in Table 1 . Females were more than males. Body mass index was $28 \pm 8 \mathrm{~kg} / \mathrm{m}^{2}$ and heart rate was $74 \pm 5$ beat $/ \mathrm{min}$. All patients received medical therapy with beta-receptor blocker or calcium channel blocker. Most patients had severe preoperative symptoms including dyspnea, chest pain, and syncope. Family history of HCM was presented in $54.7 \%$ of subjects. Hypertension,
Table 1 Clinical characteristics

\begin{tabular}{ll}
\hline Variables & Values \\
\hline$n$ & 139 \\
Age $(\mathrm{y})$ & $43 \pm 15$ \\
Male & $52(37.4 \%)$ \\
Body mass index $\left(\mathrm{kg} / \mathrm{m}^{2}\right)$ & $28 \pm 8$ \\
Heart rate $(\mathrm{beat} / \mathrm{min})$ & $74 \pm 5$ \\
SBP $(\mathrm{mmHg})$ & $113 \pm 12$ \\
DBP $(\mathrm{mmHg})$ & $73 \pm 9$ \\
Symptoms & \\
$\quad$ Dyspnea & $133(95.7 \%)$ \\
$\quad$ Chest pain & $73(52.5 \%)$ \\
$\quad$ Syncope & $33(23.7 \%)$ \\
Hypertension & $44(31.7 \%)$ \\
Diabetes & $25(18 \%)$ \\
Dyslipidemia & $101(72.7 \%)$ \\
Family history of HCM & $76(54.7 \%)$ \\
Medical therapy & \\
Beta-receptor blocker & $16(11.5 \%)$ \\
Calcium channel blocker & $43(30.9 \%)$ \\
\hline
\end{tabular}

$\widehat{S B P}$ systolic blood pressure, $D B P$ diastolic blood pressure

diabetes and dyslipidemia were prevalent in the HOCM patients. The majority of HOCM patients belonged to NYHA III.

\section{Perioperative events and complications}

Adjunctive surgical procedures were summarized in Table 2. Overall, cardiopulmonary bypass time was $133 \pm 40 \mathrm{~min}$ and aorta cross-clamp time was $85 \pm 26 \mathrm{~min}$. Postoperative intensive care unit (ICU) stay time was $3 \pm 3$ days. Mechanical ventilation time was $24 \pm 15 \mathrm{~h}$. Postoperative hospital stay time was $10 \pm 5$ days.

The 139 patients had no early death within 30 days after extensive septal myectomy. Perioperative arrhythmia was shown in Table 3. In this study, perioperative arrhythmia events included atrial fibrillation, atrial premature beat, ventricular premature beat, atrioventricular block, left bundle branch block, left anterior fascicular block and right bundle

Table 2 Adjunctive procedures

\begin{tabular}{lll}
\hline Procedure & $n(\%)$ & Age $(\mathrm{y})$ \\
\hline CABG & $11(7.9 \%)$ & $56 \pm 16$ \\
LV aneurysmectomy & $2(1.4 \%)$ & $40 \pm 17$ \\
MV replaement & $7(5 \%)$ & $46 \pm 14$ \\
MV repair & $17(12.2 \%)$ & $44 \pm 9$ \\
AV repair & $4(2.9 \%)$ & $61 \pm 19$ \\
TV repair & $6(4.3 \%)$ & $42 \pm 16$ \\
\hline
\end{tabular}

$C A B G$ coronary artery bypass graft, $L V$ left ventricle, $M V$ mitral valve, $A V$ aortic valve, $T V$ tricuspid valve 
Table 3 Postoperative arrhythmia

\begin{tabular}{lll}
\hline Arrhythmia & Number & Percentage \\
\hline Atrial fibrillation & 24 & $17.3 \%$ \\
Atrial premature beat & 7 & $5.0 \%$ \\
Ventricular premature beat & 4 & $2.9 \%$ \\
Atrioventricular block & 16 & $11.5 \%$ \\
Left bundle branch block & 34 & $24.5 \%$ \\
Left anterior fascicular block & 10 & $7.2 \%$ \\
Right bundle branch block & 5 & $3.6 \%$ \\
\hline
\end{tabular}

branch block. There was a preoperative history of atrial fibrillation in 13 patients while postoperative new atrial fibrillation occurred in 11 patients. In total, there were 16 patients suffering from atrial ventricular block after surgery. Permanent pacemaker was implanted for 8 (5.8\%) patients with complete atrioventricular block. None of the patients needed implantable cardioverter defibrillator (ICD) during early postoperative period. In addition, retraction injury to aortic valve leaflets occurred in 5 patients. One patient needed the mechanical support of intra-aortic balloon pump (IABP) immediately following surgery. Postoperative pleural effusion happened in 25 patients. Hemodialysis was used for 2 patients. Two patients were subjected to second intubation and 1 patient underwent tracheotomy. Second transfer to ICU was required for 1 patient on postoperative 7 th day.

\section{Clinical and echocardiographic follow-up}

Clinical follow-up was $5.6 \pm 0.9$ years (minimum 1.2 years and maximum 7.9 years). Four patients were lost to late follow-up. Overall survival was 100.0, 99.3, 99.3, 98.5 and $97.8 \%$ at $1,2,3,4$ and 5 years, respectively (Fig. 1). One patient died of cardiac origin and 2 patients had undiagnosed sudden death.

Follow-up outcomes indicated the symptoms were significantly attenuated and physical abilities were increased. Improvement in NYHA class was shown in Fig. 2. The proportion of NYHA III and IV decreased from preoperative 58 to $19 \%$ at 2.5 years after surgery while it reduced to $11 \%$ at 5 years after operation. LVOT gradient decreased form preoperative $84 \pm 17 \mathrm{mmHg}$ to $12 \pm 3 \mathrm{mmHg}$ at 2.5 years after surgery and it further reduced to $6 \pm 3 \mathrm{mmHg}$ at 5 years after surgery $(P<0.05$, Fig. 3$)$. Compared with the level of preoperative IVS thickness, IVS thickness decreased by $32 \%$ at postoperative 2.5 years and maintained the same low level at postoperative 5 years $(P<0.05$, Fig. 3$)$. LVID $_{\mathrm{d}}$ approximately increased by $10 \%$ at postoperative 2.5 years and 5 years, compared with the level before surgery $(P<0.05$, Fig. 3). Similarly, EF was significantly elevated at 2.5 years and 5 years after extensive septal myectomy $(P<0.05$, Fig. 3$)$. By transthoracic echocardiography detection, mitral regurgitation was ameliorated for patients after surgery. There were $52 \%$ of patients showing moderate mitral regurgitation and $8 \%$ of patients had severe mitral regurgitation before surgery. Preoperative mild mitral regurgitation existed in $40 \%$ of patients. With extensive septal myectomy, both severe mitral regurgitation and moderate mitral regurgitation disappeared. The proportion of postoperative mild mitral regurgitation increased to 89 and $11 \%$ of patients did not have mitral regurgitation any more.

\section{Discussion}

The present study included a relative large of Chinese HOCM patients who were treated by extensive septal myectomy in two hospitals. Our results showed that extensive septal myectomy significantly reduced LVOT obstruction, mitral regurgitation and HOCM-related symptoms. Cardiac function was obviously increased by surgical treatment. Extensive septal myectomy and adjunctive procedures could be an efficacious and low-risk therapy in Chinese HOCM patients. It gives predictable, immediate, and durable remodeling of the LVOT which translates into long-term control of symptoms.

\section{Extensive septal myectomy surgery in HOCM}

HOCM, as a common type of hypertrophic cardiomyopathy, is mainly characterized by asymmetric septal hypertrophy, LVOT obstruction, diastolic dysfunction, cardiac ischemia as well as arrhythmia [16-18]. The aim of medical therapy is to abolish the catecholamineinduced effects that may exacerbate LVOT obstruction

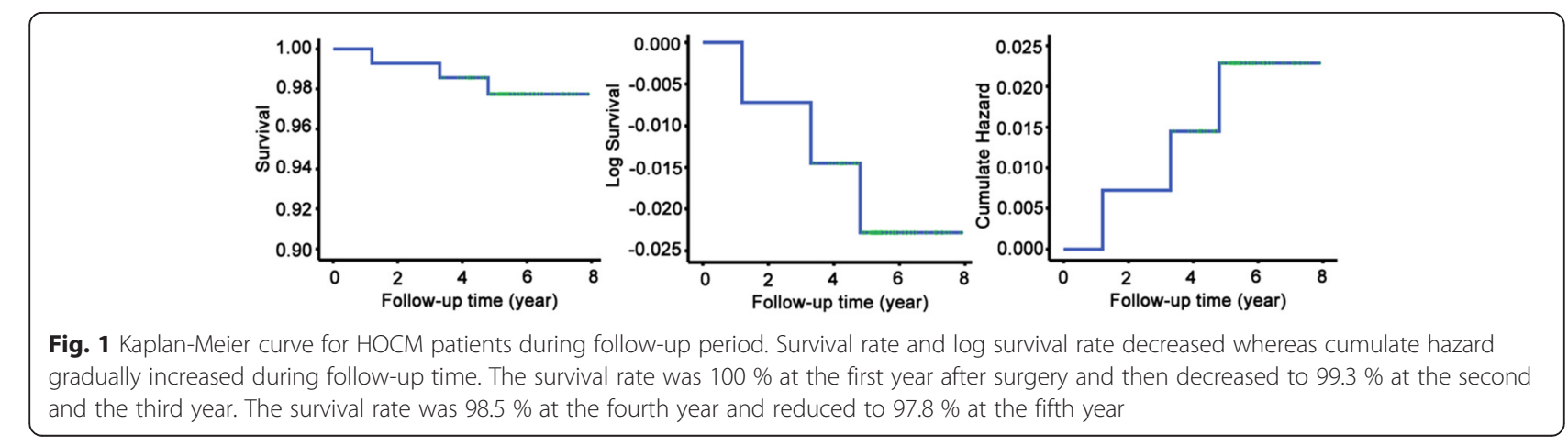




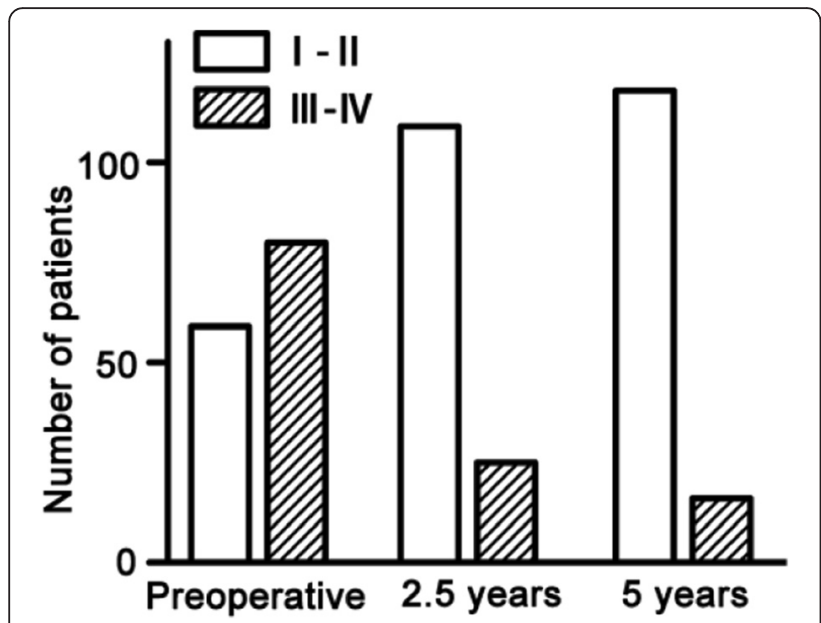

Fig. 2 Improvement in cardiac function after extensive septal myectomy. The numbers of patients in NYHA Class I-II and NYHA Class III-IV were calculated before surgery, 2.5 years and 5 years after surgery, respectively. $x^{2}$ test was performed to analyze the differences among groups. There was significant difference in preoperative and postoperative cardiac function $(P<0.05)$. There was no difference in cardiac functions between 2.5 years after surgery and 5 years after surgery $(P>0.05) . n=59$ for NYHA Class $\mathrm{H}-\mathrm{II}$ and $n=80$ for NYHA Class III-IV before surgery; $n=110$ for NYHA Class I-II and $n=25$ for NYHA Class III-IV at 2.5 years after surgery; $n=117$ for NYHA Class $\mathrm{I}-\mathrm{I}$ and $n=15$ for NYHA Class III-IVat 5 years after surgery

and to decrease heart rate which allows longer time for diastolic filling $[17,19,20]$. However, the early improvement for HOCM patients is often followed by clinical symptomatic impairments after conservative management with beta-blocker and/or calcium antagonist [21].
With septal myectomy reduction therapy, the long-term mortality for HOCM patients could significantly decrease to $1.4-1.8 \%[7,8]$.

Left ventricular septal myectomy was firstly reported by Cleland in 1963 and Morrow subsequently revealed the good clinical and hemodynamic outcomes of myectomy surgery [22]. Isolated septal myectomy mainly resected the bulge part of the hypertrophic septum. Some intraventricular anomalies such as mitral apparatus-related anomalies existed in HOCM patients. Under the condition, isolated septal myectomy could not diminish SAM of mitral valve and relieve LVOT obstruction completely [10]. Marwick et al. reported that up to $20 \%$ of patients with isolated septal myectomy were placed back on cardiopulmonary bypass because of inadequate resection [23]. An inadequate length of septal excision was the most common reason of recurrent LVOT obstruction after myectomy [24]. Extensive septal myectomy to the midventricular level, with or without shaving of the papillary muscles, could eliminate the LVOT gradient and SAM-induced mitral regurgitation [25]. Knyshov $G$ et al. performed a cohort study in HOCM patients and their results showed that LVOT gradient of HOCM patients reduced from $113.3 \pm 14.9 \mathrm{mmHg}$ to $17.3 \pm 10.2 \mathrm{mmHg}$ after extensive septal myectomy surgery [26].

\section{Follow-up outcomes of extensive septal myectomy surgery}

Until now, there are limited data addressing long-term outcomes of extensive septal myectomy in Chinese HOCM patients. Wang et al. showed that extensive septal myectomy provided excellent relief from LVOT
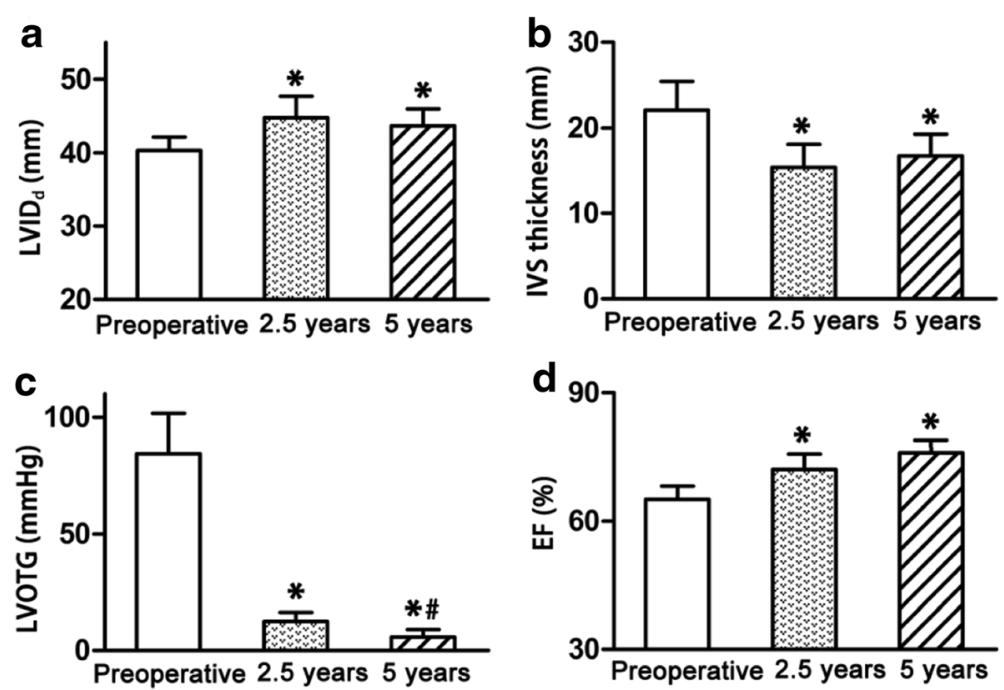

Fig. 3 Changes in echocardiographic parameters during follow-up period. a. Changes in LVID during follow-up. $\mathbf{b}$. Changes in IVS thickness during follow-up. c. Changes in LVOTG during follow-up. There was significant decrease in LVOTG at 2.5 years and 5 years after surgery. d. Changes in EF during follow-up. EF was elevated at 2.5 years and 5 years after extensive septal myectomy. LVID d: diastole left ventricular inner diameter; IVS: interventricular septal; LVOTG: left ventricular out tract gradient; EF: ejection fraction. ${ }^{*} P<0.05$ vs preoperative group, ${ }^{\sharp} P<0.05$ vs 2.5 years group 
obstruction $(91.8 \pm 25.1$ to $14.3 \pm 13.4 \mathrm{mmHg}, P<0.05)$ and satisfactory clinical outcomes for $93 \mathrm{HOCM}$ patients at early and mid-term follow-up [27]. Their study showed that the 30-day and in-hospital mortality was $0 \%$ [27]. After surgery, limiting symptoms were decreased while physical abilities were increased [27]. In our study, the resection size was extended to release adhesion of mitral papillary muscle with left ventricular wall and satisfactory operative effects and clinical outcomes were obtained. The symptoms of HOCM patients undergoing extensive septal myectomy procedure in our study were obviously mitigated after operation. Echocardiography results by our study showed LVOT gradient and septal width of HOCM patients were significantly reduced whereas their $\mathrm{LVID}_{\mathrm{d}}$, and EF were increased after surgery. The most common postoperative complication was arrhythmia, which mainly consisted of left bundle branch block, atrial fibrillation, atrioventricular block and so on. In current study, the types and prevalence of perioperative arrhythmia were similar to the previous reports [28-30].

\section{Conclusion}

Extensive septal myectomy and adjunctive procedures provide excellent relief of symptoms and improve cardiac function in Chinese HOCM patients with minimal surgical risk. Further studies with larger number and longer follow-up were expected to aim at examining the clinical outcomes of extensive septal myectomy surgery.

\section{Ethics approval and consent to participate}

The authors stated that the study had full approval from the Ethics Boards of Cangzhou Central hospital and Shandong Chinese Medical Hospital.

\section{Abbreviations \\ AML: anterior mitral leaflet; EF: ejection fraction; HCM: hypertrophic cardiomyopathy; HOCM: hypertrophic obstructive cardiomyopathy; ICU: intensive care unit; IVS: interventricular septal; LVID d diastole left ventricular inner diameter; LVOT: left ventricular outflow tract; NYHA: New York Heart Association; SAM: systolic anterior motion; SCD: sudden cardiac death; TEE: transesophageal echocardiography.}

\section{Competing interests}

The authors declare that they have no competing interests.

\section{Authors' contributions}

Concept/design: LY; Data collection/analysis/statistics: LL, X-JL, X-NK, F-JD; Drafting article: LY, Y-LM; Approval of article: LY. All authors read and approved the final manuscript.

\section{Funding}

This study was supported by National Science and Technology Supporting Program (No. 2013BAJ57B08) and Hebei Talents Fund (No.2014000021769G283).

\section{Author details}

'Second Division of Ultrasound Diagnosis, Cangzhou Central Hospital, 16 Xin-Hua-West Street, Cangzhou, Hebei 061001, People's Republic of China. ${ }^{2}$ Cardiothoracic Surgical Department, Shandong Chinese Medical Hospital,
Jinan 250011, China. ${ }^{3}$ Ultrasonic Imaging Center, Fuwai Hospital, Chinese Academy of Medical Sciences, Beijing 100037, China.

Received: 20 February 2016 Accepted: 10 May 2016

Published online: 17 May 2016

\section{References}

1. Maron BJ, Maron MS. Hypertrophic cardiomyopathy. Lancet. 2013;381:242-55.

2. Semsarian C, Ingles J, Maron MS, Maron BJ. New perspectives on the prevalence of hypertrophic cardiomyopathy. J Am Coll Cardiol. 2015;65: 1249-54.

3. Lopes LR, Syrris P, Guttmann OP, O'Mahony C, Tang HC, Dalageorgou C, et al. Novel genotype-phenotype associations demonstrated by highthroughput sequencing in patients with hypertrophic cardiomyopathy. Heart. 2015;101:294-301.

4. Roma-Rodrigues C, Fernandes AR. Genetics of hypertrophic cardiomyopathy: advances and pitfalls in molecular diagnosis and therapy Appl Clin Genet. 2014;7:195-208.

5. Loar RW, Bos JM, Will ML, Ommen SR, Ackerman MJ. Genotype-phenotype Correlations of Hypertrophic Cardiomyopathy When Diagnosed in Children, Adolescents, and Young Adults. Congenit Heart Dis. 2015;10(6):529-36.

6. Brown ML, Schaff HV. Surgical management of obstructive hypertrophic cardiomyopathy: the gold standard. Expert Rev Cardiovasc Ther. 2008;6:715-22.

7. Liebregts M, Vriesendorp PA, Mahmoodi BK, Schinkel AF, Michels M, ten Berg JM. A Systematic Review and Meta-Analysis of Long-Term Outcomes After Septal Reduction Therapy in Patients With Hypertrophic Cardiomyopathy. JACC Heart Fail. 2015;3:896-905.

8. Leonardi RA, Kransdorf EP, Simel DL, Wang A. Meta-analyses of septal reduction therapies for obstructive hypertrophic cardiomyopathy: comparative rates of overall mortality and sudden cardiac death after treatment. Circ Cardiovasc Interv. 2010;3:97-104.

9. Said SM, Dearani JA, Ommen SR, Schaff HV. Surgical treatment of hypertrophic cardiomyopathy. Expert Rev Cardiovasc Ther. 2013;11:617-27.

10. Minakata K, Dearani JA, Nishimura RA, Maron BJ, Danielson GK. Extended septal myectomy for hypertrophic obstructive cardiomyopathy with anomalous mitral papillary muscles or chordae. J Thorac Cardiovasc Surg. 2004:127:481-9.

11. Schaff HV, Dearani JA, Ommen SR, Sorajja P, Nishimura RA. Expanding the indications for septal myectomy in patients with hypertrophic cardiomyopathy: results of operation in patients with latent obstruction. J Thorac Cardiovasc Surg. 2012;143:303-9.

12. Williams LK, Rakowski H. Surgical myectomy for hypertrophic obstructive cardiomyopathy: the cut that heals. Circulation. 2013;128:193-7.

13. Ashikhmina EA, Schaff HV, Ommen SR, Dearani JA, Nishimura RA, Abel MD. Intraoperative direct measurement of left ventricular outflow tract gradients to guide surgical myectomy for hypertrophic cardiomyopathy. J Thorac Cardiovasc Surg. 2011;142:53-9.

14. Dearani JA, Ommen SR, Gersh BJ, Schaff HV, Danielson GK. Surgery insight: Septal myectomy for obstructive hypertrophic cardiomyopathy-the Mayo Clinic experience. Nat Clin Pract Cardiovasc Med. 2007:4:503-12.

15. Balaram SK, Ross RE, Sherrid MV, Schwartz GS, Hillel Z, Winson G, et al. Role of mitral valve plication in the surgical management of hypertrophic cardiomyopathy. Ann Thorac Surg. 2012;94:1990-7.

16. Melacini P, Basso C, Angelini A, Calore C, Bobbo F, Tokajuk B, et al. Clinicopathological profiles of progressive heart failure in hypertrophic cardiomyopathy. Eur Heart J. 2010;31:2111-23.

17. Gersh BJ, Maron BJ, Bonow RO, Dearani JA, Fifer MA, Link MS, et al. 2011 ACCF/AHA guideline for the diagnosis and treatment of hypertrophic cardiomyopathy: executive summary: a report of the American College of Cardiology Foundation/American Heart Association Task Force on Practice Guidelines. Circulation. 2011;124:2761-96.

18. Maron MS, Olivotto I, Zenovich AG, Link MS, Pandian NG, Kuvin JT, et al. Hypertrophic cardiomyopathy is predominantly a disease of left ventricular outflow tract obstruction. Circulation. 2006;114:2232-9.

19. Hamada M, Ikeda S, Shigematsu Y. Advances in medical treatment of hypertrophic cardiomyopathy. J Cardiol. 2014;64:1-10.

20. Musat D, Sherrid MV. Pathophysiology of hypertrophic cardiomyopathy determines its medical treatment. Anadolu Kardiyol Derg. 2006;6 Suppl 2:9-17.

21. Maron MS. My approach to clinical management of hypertrophic cardiomyopathy. Trends Cardiovasc Med. 2014;24:314-5. 
22. Cleland WP. The Surgical Management of Obstructive Cardiomyopathy. J Cardiovasc Surg. 1963;4:489-91.

23. Marwick TH, Stewart WJ, Lever HM, Lytle BW, Rosenkranz ER, Duffy Cl, et al. Benefits of intraoperative echocardiography in the surgical management of hypertrophic cardiomyopathy. J Am Coll Cardiol. 1992;20:1066-72.

24. Cho YH, Quintana E, Schaff HV, Nishimura RA, Dearani JA, Abel MD, et al. Residual and recurrent gradients after septal myectomy for hypertrophic cardiomyopathy-mechanisms of obstruction and outcomes of reoperation. J Thorac Cardiovasc Surg. 2014;148:909-15.

25. Dearani JA, Danielson GK. Septal myectomy for obstructive hypertrophic cardiomyopathy. Semin Thorac Cardiovasc Surg Pediatr Card Surg Annu. 2005:86-91.

26. Knyshov G, Lazoryshynets V, Rudenko K, Kravchuk B, Beshlyaga V, Zalevsky V, et al. Is surgery the gold standard in the treatment of obstructive hypertrophic cardiomyopathy? Interact Cardiovasc Thorac Surg. 2013;16:5-9.

27. Wang S, Luo M, Sun H, Song Y, Yin C, Wang L, et al. A retrospective clinical study of transaortic extended septal myectomy for obstructive hypertrophic cardiomyopathy in China. Eur J Cardiothorac Surg. 2013;43:534-40.

28. Vriesendorp PA, Schinkel AF, Soliman OI, Kofflard MJ, de Jong PL, van Herwerden LA, et al. Long-term benefit of myectomy and anterior mitral leaflet extension in obstructive hypertrophic cardiomyopathy. Am J Cardiol. 2015:115:670-5.

29. Steggerda RC, Damman K, Balt JC, Liebregts M, ten Berg JM, van den Berg MP. Periprocedural complications and long-term outcome after alcohol septal ablation versus surgical myectomy in hypertrophic obstructive cardiomyopathy: a single-center experience. J Am Coll Cardiol Intv. 2014;7:1227-34

30. Parry DJ, Raskin RE, Poynter JA, Ribero IB, Bajona P, Rakowski H, et al. Short and medium term outcomes of surgery for patients with hypertrophic obstructive cardiomyopathy. Ann Thorac Surg. 2015;99:1213-9.

\section{Submit your next manuscript to BioMed Central and we will help you at every step:}

- We accept pre-submission inquiries

- Our selector tool helps you to find the most relevant journal

- We provide round the clock customer support

- Convenient online submission

- Thorough peer review

- Inclusion in PubMed and all major indexing services

- Maximum visibility for your research

Submit your manuscript at www.biomedcentral.com/submit
Biomed Central 